\title{
HACIA UNA GESTIÓN MODERNA DEL SERVICIO DEPORTIVO Y RECREATIVO MUNICIPAL COSTARRICENSE
}

\author{
Allan Mosquera Vargas. M.Sc. \\ Instituto Costarricense del Deporte y la Recreación (ICODER), San José, Costa Rica. \\ Correo electrónico: amosquera@icoder.go.cr
}

\section{RESUMEN}

\begin{abstract}
El abordaje del tema de la gestión deportiva y recreativa desde un modelo integrador de las políticas y metodologías que son aplicadas en el contexto costarricense, surge a partir de la inquietud de la identificación de las necesidades reales en el campo del deporte, la recreación y la promoción de la salud, por medio del movimiento en sus diferentes manifestaciones. Esto se ha encontrado a lo largo de ocho años de trabajo, desde el Instituto Costarricense del Deporte y la Recreación (ICODER), en conjunto y en directo con las diferentes comunidades costarricenses, tanto rurales como urbanas, y en estas con sus diferentes organizaciones, llámese Asociaciones de Desarrollo Integral Comunal, Comités Cantonales de Deporte y Recreación (CCDR) y sus Comités Comunales, Alcaldías Municipales, ONGs, entre muchas otras; se toma en cuenta especialmente, el sentir producto de la vivencia, que presentan los CCDR como organizaciones responsabilizadas por el Estado costarricense de promocionar y gestionar los servicios de deporte y recreación municipal con una conveniente oferta que responda a las necesidades de todos los clientes o usuarios. De esta manera, se intenta responder a la interrogante de cómo realizar una gestión eficiente por los Comités, que a su vez responda a las necesidades de los usuarios o clientes públicos en los municipios del país, por medio de una propuesta de modelo de gestión que contribuya como un insumo más en el mejoramiento del tipo de servicio que ya existe y es gestionado por dichas organizaciones. Estructurado a partir de los elementos teóricos que definen hoy la organización y planificación, los tipos de planes en deporte y recreación como un servicio, se presenta el siguiente modelo de gestión costarricense.
\end{abstract}

PALABRAS CLAVES: gestión, servicio, calidad, municipio, deporte, recreación, planificación.

\section{TOWARDS MODERN MUNICIPAL SPORTS AND RECREATION MANAGEMENT IN COSTA RICA}

\section{ABSTRACT}

Sports and recreation management is addressed here using a model that combines the policies and methodologies applied in the Costa Rican context as a result of a concern to identify the real needs in the sports, recreation, and health promotion fields through the different manifestations of human movement. This approach has been developed during eight years of work in the Costa Rican Sports and Recreation Institute (Instituto Costarricense del Deporte y la Recreación-ICODER) together with different Costa Rican communities, both rural and urban, and local organizations, such as Comprehensive Development Community Associations, Sports and Recreation Community Boards (CCDR), Municipal Mayorships, and NGOs, among others. This article particularly takes into consideration the experience of the CCDRs as entities that have been given the responsibility by the Costa Rican Government to promote and manage municipal sports and recreation services with a convenient offering that would meet the needs of users or customers. In this way, this article is aimed at answering the question on how Boards should conduct an efficient management in a way that they also meet the needs of public users or customers in the municipalities of the country, by proposing a management model that serves as an additional instrument to improving the already existing services managed by the aforementioned entities. This study presents a model of Costa Rican management structured with the theoretical elements that currently define the organization and planning of sports and recreation as a service.

KEY WORDS: management, service, quality, municipality, sports, recreation, planning. 


\section{MHSalud}

URL www.una.ac.cr/mhsalud

\section{INTRODUCCIÓN}

Lograr una efectiva acción de promoción, desarrollo del deporte y la recreación en el país, requiere de una amplia visión de este fenómeno popular, junto a la faceta educativa en la vía escolar y el deporte de rendimiento y en un nivel más alto además de la vía federativa y el deporte para todos, donde ellos tienen su marco jurídico y social en la vía municipal de este.

Surge entonces, la necesidad imperante de abordar el tema de la gestión deportiva municipal, reconociendo el servicio gestionado por los Comités Cantónales de Deporte y Recreación como un servicio público, bajo un enfoque integral de los aspectos principales a considerar para lograr una conveniente gestión del deporte y la recreación en el ámbito comunitario (municipal), y de cara al reto que supone la oferta deportiva-recreativa en esta sociedad cada vez más demandante de ejercicio, práctica física a través del deporte y la recreación como servicio a prestar por el municipio para el logro de una mayor calidad de vida y mejores indicadores de la salud física y mental.

El enfoque que presenta el siguiente trabajo se encuentra dirigido al municipio y en especial a los Comités Cantonales de Deporte y Recreación, por ser estas las instancias inmediatas que tienen la responsabilidad social así como en sus funciones la posibilidad institucional de elevar la calidad de vida de sus habitantes en cada cantón. No solo con los servicios "esenciales": pavimentación, agua potable, alcantarillados, etc., sino también con posibilidades recreativas e instalaciones básicas para la práctica de las actividades organizadas o libres que fomenten hábitos y estilos de vida saludables.

La intención, es proponer un modelo de gestión del servicio deportivo - recreativo municipal que responda a las necesidades actuales de los usuarios o clientes, y que debe ser brindada a través de tales organismos estatales durante su período de trabajo (nombramiento por dos años), pero con el optimismo de que se pueda planificar por períodos que vayan más allá de ello.

Se estructura entonces el presente modelo por el interés de responder a la interrogante de cómo realizar una gestión competente, eficaz por los Comités que responda a las necesidades de los usuarios o clientes públicos en los municipios del país. Además busca responder no sólo al fenómeno en sí, sino, también presentar una propuesta de solución factible para contribuir en el mejoramiento del tipo de servicio que ya existe y es gestionado por dichas organizaciones del Estado costarricense.

Finalmente, se creé conveniente mencionar que cada uno de los aspectos, metodologías y programas aquí vertebrados se elaboraron con objetivos máximos en cuanto a su desarrollo, los cuales a su vez están en consonancia con los objetivos a partir de la propuesta de políticas y estrategias nacionales para el desarrollo de la actividad física para la salud, el deporte y la recreación en los cantones de este país, aprobadas por el Consejo Nacional del Deporte y la Recreación en su sesión extraordinaria número 391-2004 de septiembre del 2004; así que cada administración local (Comité) debe efectuar la correspondiente adaptación que estará dada por varios factores como: las necesidades deportivas y recreativas de la población, las pautas políticas que se fijen los gobernantes, los recursos técnicos, humanos y materiales propios y los equipamientos públicos disponibles, entre otros elementos.

En adelante, para efectos de esta lectura, se usará el término "Comité" o "Comités", cuando se refiera a más de uno, por el de los Comités Cantonales de Deporte y Recreación (CCDR). 


\section{MHSalud}

URL www.una.ac.cr/mhsalud

\section{1.- LA GESTIÓN}

Al hablar del término gestión, no cabe duda que tiene múltiples y diferentes acepciones, una de ellas y sobre la cual se ha sustentado el Plan Nacional de Fortalecimiento y Acreditación de los Comités por el ICODER es el siguiente: "Conjunto de la organización deportiva, la planificación de las actividades a desarrollar, su puesta en práctica y el control subsiguiente; todo ello enmarcado en el contexto de la existencia de necesidades deportivas ciudadanas, reales o potenciales, y su satisfacción de la manera más racional posible en cuanto a rendimientos sociales, deportivos y económicos se refiere" (Mestre y García, 1999. pp. 18).

Visto de otro modo, se refiere a aquel conjunto de actividades y medios necesarios para una correcta utilización de los espacios del deporte y la recreación física-deportiva, con la meta de permitir a los usuarios el desarrollo de sus actividades en las mejores condiciones posibles, adoptando las medidas recomendables con criterios de economía mediante el empleo racional de los recursos disponibles para obtener los máximos resultados.

Sin embargo, y de acuerdo con Campos (2000), este incremento de la práctica deportiva no ha sido en modo alguno unidireccional si se quiere aplicado a este contexto, por cuanto ha existido un marcado proceso de diferenciación de la demanda de esta práctica al que no ha sabido responder adecuadamente el sistema de la oferta deportiva y recreativa costarricense. En ese sentido, ello ha ocasionado que la oferta actual gestionada desde los municipios, diste mucho de ir en consonancia con la diversidad y continua evolución de la demanda. Como ejemplo se observa algunos datos para entender este criterio:

En la encuesta de servicios que fue aplicada en octubre del 2004 a los Comités de todo el país, al consultárseles sobre la disponibilidad en el uso de sus instalaciones deportivas, sólo el $68 \%$ de ellos manifiesta que sí las utilizan, y el restante $32 \%$ indica que no, lo cual hace notar que existe un alto porcentaje con carencia de servicios que se oferten para un amplio sector de la población costarricense (Mosquera, 2004).

Del mismo modo, al preguntar sobre la definición de su servicio para el cantón, menos de la mitad de todos los comités del país (49.4\%) manifiestan tenerlo definido, mientras que el restante $50.6 \%$ no tiene definido su servicio y por lo tanto tampoco la oferta del mismo (Mosquera, 2004).

En otras palabras, esa diversidad de la que se habla antes, es precisamente, uno de los condicionantes que más van a exigir nuevas fórmulas organizativas y de gestión de los servicios o actividades físico deportivas, según Campos (2000), a fin de coordinar la correcta interacción entre la oferta y la demanda deportiva. O sea, para quienes están inmersos en este campo, se tiene al frente el reto de resolver la escasa adecuación de la oferta a la demanda deportiva y recreativa como fruto de un incorrecto modelo de gestión y comercialización en este terreno.

Ahora bien, en el campo de las ciencias del deporte, el mundo ha evolucionado considerablemente en cuanto sus enfoques y formas para desarrollarlo, en ese sentido, ahora una de las formas más aceptadas se refiere a vías o ejes conceptuales sobre los cuales se fundan los diferentes servicios deportivos y recreativos a disfrutar por las personas en el municipio. De acuerdo con Mestre y García (1999, pp. 21), se observa cuales son estos: 


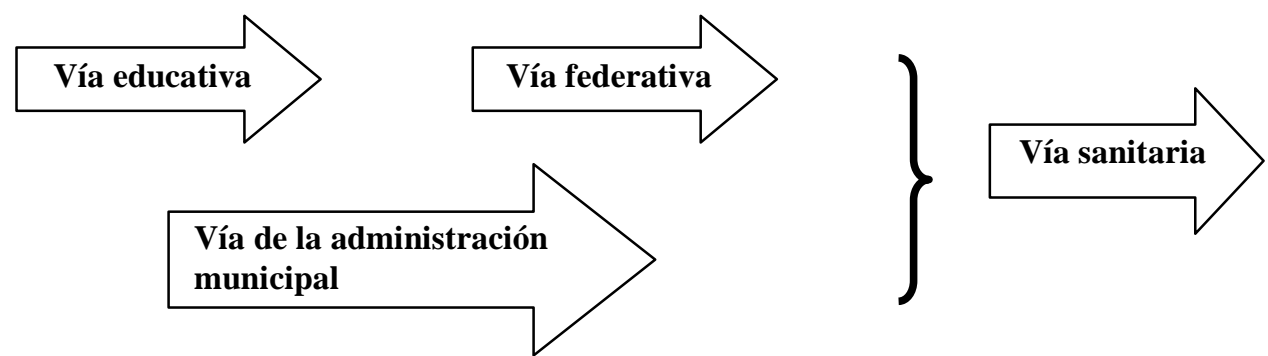

Vía educativa. Hace referencia a la educación física escolar, al deporte y la recreación propuesta que ha sido exigida en el ámbito de la educación primaria y secundaria, prolongándose hasta la finalización de los estudios universitarios. Su lugar de actuación por tanto es el centro escolar: las escuelas, los colegios e institutos, etc.

Vía federativa o de las asociaciones. Posee un carácter voluntario y está inmersa plenamente en el ámbito del asociacionismo fundamentalmente deportivo aunque también de otro tipo como lo puede ser el netamente recreativo. El desarrollo de esta vía está regido por la Ley de Asociaciones y Federaciones, así como, por el reconocimiento y vínculo con otras leyes conexas como la Ley del Deporte, Ley General de Salud, etc.

Vía municipal, o de las Administraciones públicas locales. Sus acciones transcurren en el contexto del municipio, de las comunidades y barrios, encaminadas al fomento del deporte ciudadano como servicio público, de la actividad física como instrumento para la ocupación del tiempo libre, y la promoción de la salud física y mental. Esta vía está regulada básicamente por la Ley del Deporte y la Ley del Régimen Municipal, y por los otros textos referidos a la Administración pública local.

Vía sanitaria. Muy relacionada con las otras, fundamentalmente con la municipal, por cuanto ambas tienen como razón de ser la salud de los ciudadanos. En ese sentido, debe de entenderse que esta no es asunto que dependerá sólo de los médicos, sino también de las decisiones que tome cada uno en favor de mantener su salud y de prevenir la enfermedad, por lo que tanto individuos como los grupos organizados, las instituciones y los gobiernos locales tienen en sí mismos la responsabilidad para adoptar y favorecer la práctica de un estilo de vida activo y saludable por medio de la actividad física, la recreación y el deporte. (Mestre y García, 1999. pp. 21).

\section{2.- ELEMENTOS DE LA ORGANIZACIÓN-PLANIFICACIÓN DEL DEPORTE Y LA RECREACIÓN MUNICIPAL}

La planificación y organización de ello se fundamenta en la prestación del servicio deportivo recreativo que atiende esas necesidades, además las de salud física y mental, de estilos de vida saludables, de un uso activo del tiempo libre. De acuerdo con Campos (2000), por lo que respecta a los intereses concernientes, procede al análisis de la gestión de los mismos desde una consideración vista como un proceso o conjunto de ellos más que como un conjunto de áreas de actividad. A este respecto, cabe entonces recordar que es preciso examinar el fenómeno de la gestión deportiva y recreativa, más que área de contenido, o grupo de procesos conformadores de la actividad de 


\section{MHSalud}

URL www.una.ac.cr/mhsalud

gestión, y a través de la identificación de una serie de subprocesos dentro del general, así se es más capaz de identificar los subprocesos que generarán los resultados de calidad en la dimensión de la promoción deportiva y recreativa.

Para una mejor comprensión de lo que hasta aquí se ha dicho, se intentará explicar de una forma más sencilla. Así, de lo que se trata es que las administraciones locales asuman el protagonismo que les corresponde y se hagan cargo de esta área, vista como un proceso de servicios, fundamentalmente si se tiene en cuenta el concepto que las actividades físicas y deportivas, deben ser consideradas como un servicio público, que por consiguiente permite y debe crear estructuras que planifiquen y organicen la gestión de los bienes (instalaciones e infraestructura deportiva) y de las actividades físicas, deportivas y recreativas. No obstante, como bien lo apunta Campos (2000), se ha de tener muy presente que se debe distinguir de manera muy clara y de acuerdo con el modelo que se aplique la relevancia en el contexto de la gestión de la oferta de estas; es decir, aquella que alude a la existencia de dos calidades, a saber, técnica y funcional o de proceso.

En este sentido la calidad técnica del servicio hace referencia al "¿qué se recibe?", mientras que la funcional incide en "¿cómo es recibido el servicio?"; de manera que se puede entender que la primera se manifiesta en el resultado técnico o el que da al final del proceso de producción del servicio, mientras que la última centra su atención en el desarrollo del proceso, en la manera en la que el servicio es proporcionado al cliente (Campos, 2000, pp. 2). Del mismo modo Campos (2000), sustentado en el modelo de Christian Grönroos, manifiesta que dentro de la calidad técnica se encuentran los siguientes procesos: el servicio básico, los facilitadores y reforzadores (bienes), por su parte, integran la calidad funcional los siguientes procesos: la accesibilidad al servicio, las interacciones y la participación del cliente. Antes de continuar, se identificarán estos elementos, con un ejemplo concreto:

Figura 1. Concepto de servicio de una actividad física deportiva y recreativa de acuerdo a su calidad técnica.

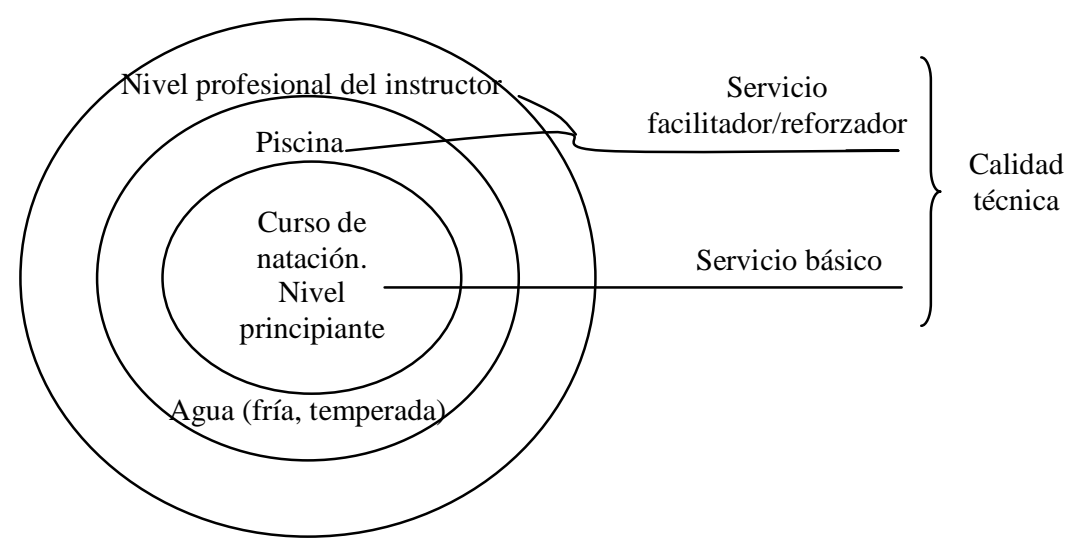




\section{MHSalud}

URL www.una.ac.cr/mhsalud

Figura 2. Concepto de servicio de una actividad física deportiva y recreativa de acuerdo a su calidad funcional.

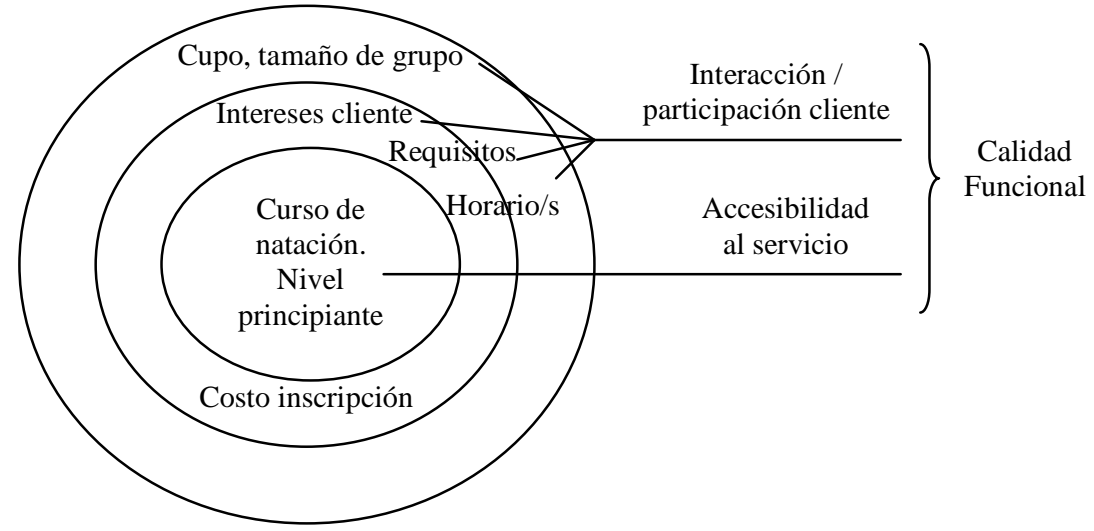

Visto lo anterior, es importante definir qué se puede entender por el concepto de: "servicio deportivo y recreativo municipal". Como este será la base de lo que se propone en el presente modelo de gestión, de acuerdo con Stoppani (2000, pp. 175) se entenderá por él: conjunto de acciones físicas, deportivas y recreativas que programe y desarrolle la organización política de ese nivel. La misma puede llevarse a cabo con personal propio o contratado y en instalaciones públicas o privadas.

Se toma como referencia la definición de servicio dada en el párrafo anterior, dentro de ésta se encuentra la calidad técnica, (el “¿qué?”), que según Campos (2000), se puede hablar de un paquete básico de servicios que en su seno hacen acto de presencia los siguientes subprocesos: los programas de actividades físico deportivas y recreativas como servicio básico; y otra serie de servicios tales como recepción, médicos, educativos, entre otros a localizar dentro de los llamados facilitadores o los reforzadores, pero esto dependerá de la valoración del cliente. Además, adicionalmente se ha de contemplar el "¿cómo?" (Calidad funcional), misma que en ocasiones es totalmente desatendida quizás, producto de la propia formación de los gestores deportivos más próxima a los aspectos técnicos de la actividad física deportiva. Cuando sucede esto, donde lo único que se ha de gestionar son los programas de actividades y las instalaciones, cabe entonces hablar de una miopía en este sentido.

Para entender mejor esta calidad funcional, se puede mencionar entonces otros subprocesos tales como los de accesibilidad al servicio de actividad físico deportiva y recreativa, de las diversas interacciones que tienen lugar durante la prestación del servicio (interacciones entre el cliente del servicio y el personal de contacto o promotor de deportes, recreación, etc.; entre el cliente y el soporte físico -instalaciones, equipamiento, etc.; entre el cliente y los sistemas de prestación del servicio; entre el cliente y otros clientes también presentes durante el proceso de prestación del servicio), y finalmente, la participación también del cliente en la producción del servicio de actividad físico deportiva o recreativa.

Lo que se ha reseñado hasta ahora debe estar basado o dicho en otras palabras, respaldado como bien lo decía anteriormente, por una definición previa del servicio que se quiere brindar en este campo. En ese sentido Campos (2000), propone que la definición de servicio es el concepto paraguas que va a guiar el diseño y desarrollo de los demás elementos de la oferta (paquete básico de servicios, interacciones, accesibilidad, participación y comunicación comercial). 


\section{MHSalud}

URL www.una.ac.cr/mhsalud

Figura 3. Desarrollo de la organización municipal para la gestión deportiva-recreativa.

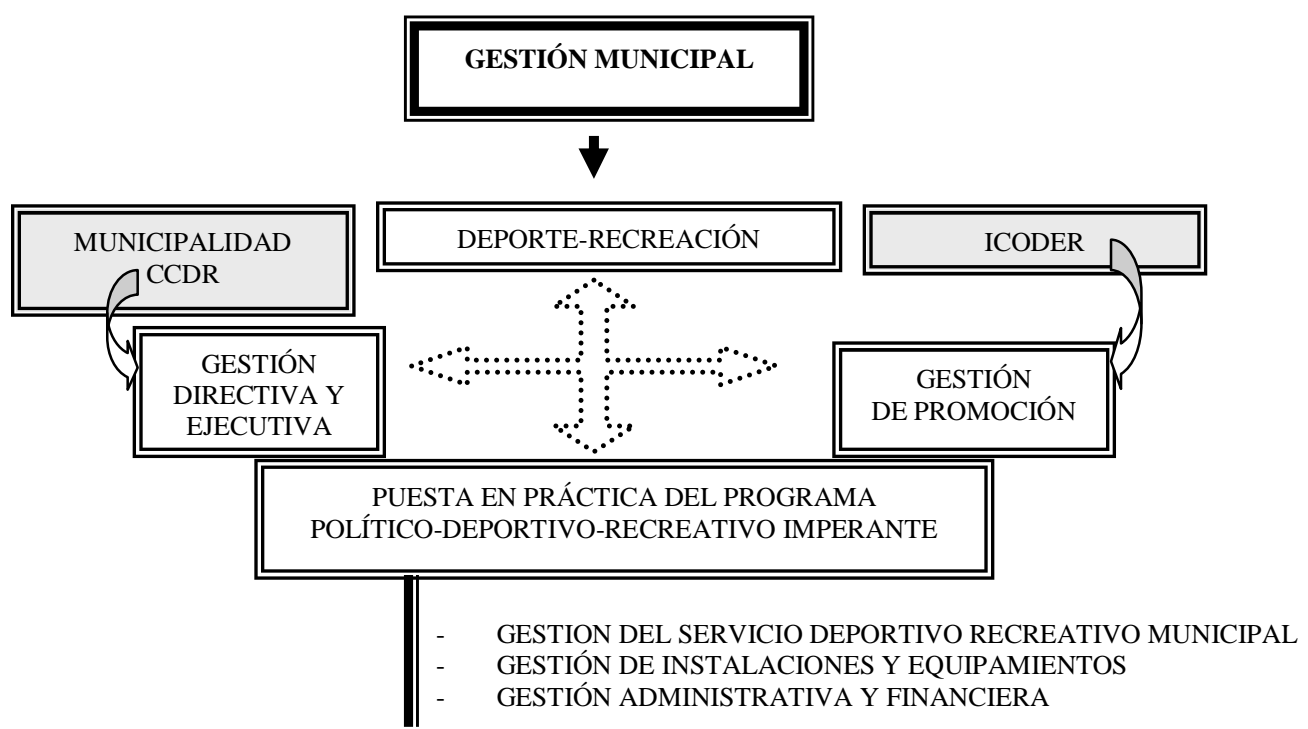

Esquema modificado por Mosquera para Costa Rica. Proceso gestor del deporte municipal. (Mestre y García, 1999, pp. 27).

Como se aprecia en la figura $\mathrm{n}^{\mathrm{o}} 3$, una propuesta para el desarrollo del servicio deportivo y recreativo municipal, que responda a las necesidades reales de las personas en cada comunidad, dependerá fundamentalmente del modelo de gestión que esté desarrollando la Municipalidad. Por lo que el tipo de gestión que esta tenga en su práctica, sea directa, la misma se encarga de ofertar y ejecutar los servicios y actividades; indirecta, que facilita la oferta de los servicios por medio de convenios o contratos, concesiones, etc.; o mixta combinación de las dos anteriores, es claro que un área social prioritaria a desarrollar será el deporte y la recreación ofertados a través de un servicio como el medio para lograr mejorar y mantener la calidad de vida de los habitantes en su cantón, pero además, cuyos beneficios incidirán directamente en la productividad y desarrollo social y estructural de cada comunidad.

Tres actores muy importantes participan en el desarrollo de este modelo, el primero, está representado por el Instituto Costarricense del Deporte y la Recreación (ICODER), quien viene a cumplir una función rectora y reguladora dada por la Ley 7800 de creación de dicho instituto y su reglamento, pero que se desarrolla por medio de acciones de promoción y de capacitación de las personas, líderes comunitarios involucrados en el quehacer deportivo y recreativo nacional, así como, de participación y ejecución directa de los programas, proyectos y actividades que se practican en las comunidades del país; y por medio del fortalecimiento de los conocimientos, las motivaciones hacia la práctica permanente de la actividad física y estilos de vida saludables, de la competente y eficaz ejecución los procedimientos para el desarrollo del deporte y la recreación, para la puesta en práctica del programa local en armonía con las políticas nacionales para el desarrollo del deporte y la recreación.

El segundo y tercer actor, lo constituyen la Municipalidad de cada cantón en primera instancia, y cada uno de sus respectivos Comités Cantonales de Deporte y Recreación. De manera que, le 


\section{MHSalud}

URL www.una.ac.cr/mhsalud

corresponderá a cada municipalidad ejercer una función directiva que le permita asesorar, administrar, controlar y evaluar los recursos y resultados invertidos por medio de su Comité para responder a las necesidades ciudadanas y mejorar la calidad de vida de sus habitantes. Por su parte el Comité, de la misma manera tendrá que ejecutar una labor directiva similar a la desarrollada por la municipalidad con ellos, ejerciéndola éstos para sí mismos, y para todos los comités comunales, asociaciones y grupos deportivos y recreativos afiliados, con el fin de ejecutar con efectividad los recursos asignados para el desarrollo de sus actividades durante el periodo de vigencia de su gestión. Y se agrega este concepto (efectividad), porque basado en la experiencia recopilada del trabajo a lado de muchos comités del país, se ha podido observar que aunque se cumplan los objetivos trazados por una institución municipal, entiéndase en este caso cualquier comité del ámbito nacional, no siempre los clientes o usuarios de los servicios resultan beneficiados. En otras palabras, esto resulta porque muchas veces se fijan o definen objetivos que no responden a las necesidades reales de la población definida como meta; es entonces que se puede ser eficiente pero no efectivo.

De igual forma se puede interpretar que corresponderá a los Comités, según lo establecido en el Código Municipal (Código Municipal, 2001, arts. 164, 170), realizar la labor ejecutiva de sus programas y proyectos, o bien, delegándola en otras instancias de la comunidad con el consentimiento de la misma municipalidad. En concreto, serán los llamados a ejecutar las actividades a través de un servicio integral que responda a las necesidades ciudadanas, y que además responda a criterios de economía de la correcta utilización de los fondos públicos en beneficio de la población por medio de las actividades ofertadas y desarrolladas mediante el servicio deportivo y recreativo municipal.

Ahora bien, de acuerdo con Martínez (2003) para hacer teoría de planificación en la gestión del servicio deportivo y recreativo municipal, es conveniente unificar también la esencia de varios procesos de planificación diferentes pero necesariamente complementarios y concluyentes en el ámbito municipal: como primero de ellos, identificar y comprender que la Municipalidad como empresa sigue un planteamiento económico y productivo (perspectiva empresarial); segundo, como entidad pública debe de garantizar la participación de los representantes de los ciudadanos y respetar las normas que rigen su funcionamiento (perspectiva local); y tercero, como potencial instrumento para satisfacer las necesidades de los ciudadanos debe conseguir cambios, adaptaciones o modificaciones hacia valores y actitudes deseables (perspectiva de la animación sociocultural).

La oferta del servicio físico deportivo, recreativo municipal, como cualquier otro proyecto socio cultural hace referencia a un conjunto de actividades concretas, interrelacionadas y coordinadas entre sí, que se realizan con el fin de producir determinados bienes y servicios capaces de satisfacer las necesidades o resolver ciertas carencias o problemas de los clientes demandantes (Martínez 2003). De acuerdo con esto, cabe decir que la planificación de este servicio deberá entenderse entonces como el conjunto de actividades coordinadas y sucesivas, unitariamente encaminadas a la consecución de un logro y obviamente no exentas de continuos controles y reajustes. Pero además, en consonancia con Martínez (2003, pp. 2) tal acción consiste en utilizar un conjunto de procedimientos mediante los cuales se introduce una mayor racionalidad y organización en un conjunto de actividades y acciones articuladas entre sí, que previstas anticipadamente, tienen el propósito de influir en el curso de determinados acontecimientos con el fin de alcanzar una situación elegida como deseable, y mediante el uso eficiente de medios y recursos escasos o limitados. 


\section{MHSalud}

URL www.una.ac.cr/mhsalud

En tal sentido y de acuerdo con Martínez (2003), toda actuación básica que dirige cualquier proyecto de oferta de este tipo de servicios al que se ha hecho referencia, se asienta en cuatro elementos claves, a saber: prever tareas-actividades (interrelacionadas y encaminadas hacia) finalidades-objetivos-metas (para) satisfacer necesidades o resolver problemas (mediante) el uso eficiente de medios y recursos

Por lo tanto, como estrategia metodológica propuesta para responder y ejecutar el modelo planteado se proponen tres grandes tipos de planes, que son según el conocimiento de la realidad nacional, los que estructuralmente operan la acciones de los Comités Cantonales:

Planes:

1. Gestión del servicio deportivo y recreativo municipal

2. Gestión de instalaciones y equipamientos para la oferta del servicio deportivo y recreativo municipal

3. Gestión administrativa y financiera

\section{1.- EL PLAN DE GESTIÓN DE SERVICIO DEPORTIVO Y RECREATIVO MUNICIPAL}

El desarrollo del deporte y la recreación en la vía municipal, supone un constante ajuste entre la demanda y la oferta que se presenta, por lo tanto, su planificación deberá permitir una agilidad temporal para los dos años de vigencia de nombramiento de los Comités, pero que además se proyecte para los años siguientes como parte de los compromisos municipales y de los Comités entrantes, buscando con ello garantizar la continuidad y sostenibilidad de los programas que impacten positivamente en el desarrollo de la propia comunidad y de las políticas nacionales para el desarrollo del deporte y la recreación.

Asimismo, la oferta siempre deberá ser producto de un estudio de las necesidades poblacionales, potenciales o reales, considerando el conjunto de variables que actúan, tales como tradiciones, tendencias, recursos naturales, edades... de cada población. Todo ello estará supeditado a los propios recursos del municipio y a las posibilidades para generarlos.

Ahora bien, retomando el enfoque de perspectiva empresarial como lo apunta Martínez (2003, pp. 3 ), para la definición de esa oferta de servicio corresponde hablar y considerar el seguimiento de cuatro fases como son: los objetivos, las políticas, los planes y los procedimientos. Entonces, dentro de los objetivos de planificación del servicio se pueden concretar los siguientes elementos: beneficio, productividad, eficiencia, supervivencia, continuidad, estabilidad, desarrollo, crecimiento, adaptación y flexibilidad, proceso de mejora de imagen, ampliación de la cuota de mercado, calidad, etc. Pero esta perspectiva de trabajo no debe estar alejada o divorciada del enfoque de la administración local, la cual tiene que salir concretamente de las necesidades deportivas y recreativas ciudadanas, a partir de la cuales se constituye la política deportiva municipal.

Como siguiente paso de ese proceso de planificación inicial en donde se detectan las necesidades propias del cantón y con ellas todas las variables que las condicionan, vamos a definir los programas de actividades, es decir, sustentar las actividades que se desarrollen en el cantón según sus particularidades y que le dan contenido al servicio como tal. Según Martínez (2003, pp. 4), una 


\section{MHSalud}

URL www.una.ac.cr/mhsalud

buena aproximación de las necesidades de la población en la Administración Local, se puede conocer mediante:

- Procedimientos de investigación social aplicada al deporte y la recreación social, p.ej. encuestas, etc.

- Planteamientos filosóficos y fisiológicos de las necesidades humanas.

- Consecuencias de los conceptos: deporte para todos, actividad física para la salud, deporte y recreación para una mejor calidad de vida; desde el análisis de la filosofía política.

- El deporte, la recreación, y su relación con la salud.

Por otro lado, de acuerdo con el contexto, esa oferta de programas y actividades brindada a partir de los Comités no debe competir con la privada, de forma que se interfieran o se ahoguen. Más bien, ésta debe llegar a aquellos sectores que no son alcanzados por la oferta privada y en todo caso constituirse como un servicio que atiende las demandas ciudadanas, sobre todo los sectores más desfavorecidos.

Por ello y siguiendo con la línea de pensamiento hasta aquí desarrollada, no se debe descartar la tercera perspectiva de la que nos habla Martínez (2003), que es reconocida como: la de animación sociocultural o en este caso más concreto, de la animación físico deportiva como una de las formas de esta, la cual posee un carácter instrumental, emancipador, terminal, continuo; en la cual los proyectos deportivos, recreativos municipales por su carácter representativo y consustancial a las necesidades de los ciudadanos, deben dar cabida a todas las tipologías de prácticas físicas deportivas y físico recreativas que cumplan el efecto dirigido a satisfacer la demanda. Pudiendo todas ellas asumir en mayor o menor medida los planteamientos restringidos de la animación sociocultural con determinadas prácticas (Martínez, 2003).

En consonancia con Martínez (2003, pp. 5), se comparte la concepción de la planificación social como una transformación de la realidad social la cual se refiere fundamentalmente al cambio cualitativo y cuantitativo en la elección y utilización de los elementos satisfactorios para cubrir las necesidades fundamentales.

De forma genérica se menciona algunos programas que pueden resultar de los planes inicialmente propuestos por los Comités, y que presentan concordancia con lo establecido por las políticas nacionales para el desarrollo de la actividad física, el deporte y la recreación para la salud promovidas por el ICODER. No obstante, los mismos pueden tomarse como una guía que puede ser adaptada a la realidad de cada cantón y comunidad.

\section{De acuerdo con los objetivos estrictamente apegados a los servicios deportivos y recreativos:}

- $\quad$ Edades

- Espacios deportivos existentes en el municipio

- Espacios naturales y urbanos de uso deportivo y recreativo

- Por temporadas

- Por ciclos

- Etc.

Según el modelo optado, cada uno estará constituido por el conjunto de programas específicos, que pueden ser, entre otros: 


\section{MHSalud}

URL www.una.ac.cr/mhsalud

- Escuelas deportivas y recreativas municipales básicas

- Escuelas recreativas de vacaciones

- Escuelas de iniciación deportiva

- Escuelas deportivas específicas

- Juegos deportivos - recreativos municipales (Juegos comunales)

- Juegos deportivos escolares (Juegos deportivos estudiantiles)

- Clubes deportivos y recreativos

- Actividades físicas de mantenimiento para adultos

- Cursos específicos de natación por edades

- Carreras urbanas

- Días de bicicleta, patines...

- Competencias de nado en aguas abiertas...

- Actividades al aire libre o en la naturaleza

- Campamentos, escalada, senderismo...

- Actividades náuticas

- Actividades para el adulto mayor

- Actividades para personas con discapacidad

- Aeróbicos

- Yoga y actividades similares

- Programas de fomento del asociacionismo deportivo y recreativo, etc.

Los programas de difusión, por su naturaleza un tanto más complejos en su definición, pueden tener diferentes objetivos, perseguidos por programas a tal efecto diseñados. Por ejemplo:

- Dar a conocer el propio servicio deportivo y recreativo municipal

- Dar a conocer las actividades programadas por el servicio deportivo y recreativo municipal (los planes, los programas, los proyectos)

- Difundir la recreación y el deporte en general, desde diferentes perspectivas, histórico, cultural, preventivo de enfermedades, de salud, de ocio, etc.

- Actividades de promoción de estilos de vida saludables y del uso activo del tiempo libre.

- Difundir la celebración de días o eventos importantes para el país: día nacional del deporte, día mundial de la salud, día internacional del desafío, día mundial del no fumado, día mundial sin drogas, día mundial del corazón, etc.

- Actuar de vehículo de comunicación deportiva con los ciudadanos

- Difundir los aspectos técnicos de los deportes

- Difundir los logros como resultado del servicio deportivo y recreativo municipal en la localidad

- Etc.

Dentro estos programas se pueden incluir aquellos correspondientes a la organización de:

- Congresos y/o jornadas sobre temas de actividad física, deporte y recreación

- Seminarios de tecnificación

- Charlas, mesas redondas, coloquios...

Sin embargo, no será suficiente establecer una lista de programas que son los comúnmente más conocidos por la comunidad o en respuesta a los que históricamente se ha participado tanto dentro del cantón como de intercambio con otras comunidades o zonas del país, ya que dependiendo del 


\section{MHSalud}

URL www.una.ac.cr/mhsalud

diagnóstico se encontrará que los mismos por si solos no han podido responder a las necesidades y demandas actuales de la población, más bien, como lo plantea Roque (2004) en su documento "Políticas y Estrategias para el Desarrollo de la Actividad Física para la Salud, el Deporte y la Recreación en los Cantones del País", en su apartado "Debilidades de los Comités Cantonales de Deporte y Recreación", generan frustración por la inversión en tiempo, materiales y dinero contra los pobres resultados obtenidos dependiendo del programa en el que participan.

Para responder a esta inquietud, es necesario complementar con objetivos claros cuál será el propósito a alcanzar con la oferta de dichos programas organizados a través de un servicio deportivo y recreativo municipal, que permita responder a esas necesidades encontradas y que además lleve al logro de los mismos utilizando cada uno de los programas (actividades) como un medio y no como el fin último. En otras palabras, cuando se propone que el Comité planifique, organice y ejecute, es decir oferte: p.ej., el programa de actividades físicas de mantenimiento para adultos, se debe tener bien claro que necesidades se estarán satisfaciendo con estas actividades y cuales son los resultados esperados, pero también que los deseos de los beneficiarios se vean representados en ellas, ya que de lo contrario difícilmente las actividades propuestas llenaran sus expectativas y por lo tanto sigan siendo demandadas de manera que se puedan mantener en el tiempo.

De igual forma pasaría con un programa orientado bajo la línea meramente deportiva, como lo puede ser: juegos deportivos - recreativos municipales (juegos comunales). En este caso, no se trata sólo de que el Comité cumpla con la ejecución de ellos y trate de desarrollar la mayor cantidad de actividades y del agrado de la gente en su comunidad, principalmente adultos, sino que también deberán responder a criterios de eficiencia. Es decir, no se trata solo de ver gastar todo el presupuesto que se le asigna y demostrar así a la comunidad que se organizaron unos juegos modernos, del nivel de los Nacionales, y que se empleo lo último en tecnología del deporte si se quiere, sino que además, habrá que responder si se logró que la comunidad se integrara más, que participara de una forma más activa y no tanto como espectadora, que con ello se crearán más grupos permanentes donde las personas disfrutan y se ejercitan en beneficio de su salud física y mental, que se logra además reducir los niveles de violencia juvenil, y que se identifiquen los prospectos con cualidades físicas, mentales y emocionales para integrar las diferentes selecciones cantonales que representaran al cantón y porque no, al país en niveles de competición mayores, etc.

Como está claro que cada administración deportiva local debe fijar sus propios objetivos, es también lo suficientemente claro que estos no se pueden alejar de la filosofía y orientación que dictan las políticas nacionales para el desarrollo de la misma, por eso, a continuación se presenta una guía general para la formulación de objetivos los cuales se encuentran en absoluto apego a los lineamientos nacionales, y que además pueden servir de base a los Comités para sus procesos de planificación, organización, ejecución y control de toda la acción que tienen que desarrollar en sus cantones.

Para iniciar, se empezará por definir que son objetivos. De acuerdo con Stoppani (2000, pp. 29), se puede entender de la siguiente manera: “... propósitos que se esperan alcanzar dentro de un periodo, mediante la ejecución de actividades insertas en un programa". Sobre la base de esta definición, se puede decir que los Comités como entidades públicas tienen la función de ordenar, fomentar, financiar y fiscalizar las actividades de índole deportivo y recreativo, pero además de la actividad física para la salud y del uso positivo del tiempo libre en todos los sectores de la población; tienen también la obligación moral y ética, sino fuese política de trabajar con base a objetivos, estrategias y actividades que respondan a esta realidad nacional, por ello, los objetivos 


\section{MHSalud}

URL www.una.ac.cr/mhsalud

podrán dividirse y plantearse de acuerdo al tiempo en que podrán cumplirse. A modo indicativo una forma sería:

Objetivo general: este es intemporal, ya que es casi imposible de cumplir en un espacio de tiempo relativamente breve, como es el que se tiene en la práctica asidua y sistemática de la actividad física para la salud, por ejemplo. Su razón es que de él se desprenden los restantes objetivos cuyo cumplimiento si es factible en un periodo de tiempo más corto.

Objetivos específicos: estos deben establecerse sobre la base de un tiempo de finalización, son difíciles pero alcanzables. Deben definirse si son factibles con la participación de todas las fuerzas activas de la localidad.

Objetivos operativos: son los que se encuentran enunciados en cada una de las actividades de los distintos programas. Tienen por lo general un tiempo breve para su cumplimiento, se pueden dar en un día, semana, mes o en un tiempo mayor.

\subsubsection{TIPOS Y EJEMPLOS DE OBJETIVOS PARA UNA ADMINISTRACIÓN LOCAL}

\section{OBJETIVO GENERAL (INTEMPORAL)}

Fomentar y desarrollar la actividad física, el uso positivo del tiempo libre mediante la recreación, el deporte de forma permanente, sistemática, a partir de la operación de un servicio deportivo, recreativo permanente y dinámico en el cantón. Destinado a favorecer la salud de los pobladores y el aprovechamiento en el empleo de su tiempo libre, favoreciendo además, la formación, detección y seguimiento de los prospectos y talentos deportivos del municipio.

\section{OBJETIVOS ESPECÍFICOS. A CORTO PLAZO (UN AÑO)}

- Acercar la actividad física, la recreación y el deporte a toda la población, a fin de ocupar positivamente su tiempo libre.

- Desarrollar y mejorar la práctica de la actividad física, la recreación y el deporte en todos sus niveles, aumentando cuantitativamente su práctica.

- Difundir en la población los valores y beneficios que estas actividades otorgan a los practicantes y a la sociedad.

- Coordinar con las instituciones correspondientes actividades, programas, calendarios, etc., a fin de evitar superposiciones.

- Resolver las carencias de horarios, espacios recreativos y deportivos mínimos en los lugares que fuesen necesarios.

- Iniciar un equipamiento recreativo, deportivo público y mejorar, mantener los existentes.

- Ayudar a los deportistas de alto nivel por medio de estímulos, reconocimientos que le faciliten su preparación y formación, como parte del desarrollo del deporte. 


\section{OBJETIVO A MEDIANO PLAZO (DOS AÑOS)}

- Colaborar e impulsar con el crecimiento técnico de los dirigentes y miembros de las organizaciones deportivas y recreativas del cantón (educadores físicos, administradores, técnicos o entrenadores, líderes y voluntarios, etc.).

- Concretar una mayor y mejor coordinación con las instituciones gubernamentales, recreativas, deportivas y ONGs dispuestas a trabajar en programas comunes.

- Elaborar una serie de trabajos de investigación, de medición de impacto, y concretar intercambios entre organismos similares.

\section{OBJETIVOS A LARGO PLAZO (CUATRO AÑOS O MÁS)}

- Fomentar, divulgar, planificar, coordinar, ejecutar, asesorar e implantar la práctica de las actividades físicas, recreativas y deportivas ofertadas a través del servicio deportivo y recreativo municipal en todo el ámbito municipal, en todos los niveles y estamentos, con el fin de hacer realidad el derecho de todo ciudadano a ejercer su práctica.

\subsection{2.- IMPLEMENTACIÓN DE LAS ACTIVIDADES A DESARROLLARSE EN EL CANTÓN}

Se retomará la propuesta de programas antes presentada para que los Comités la desarrollen en su comunidad ya sea como actividades aisladas o programas con objetivos integrados a una política de desarrollo nacional y local.

Un aspecto importante es que esta realidad indica que no existe una práctica masiva de la actividad física, la recreación activa y de deportes; así se nota que el escolar carece de objetivos a mediano y largo plazo, por lo tanto de continuidad suficiente para volcar el aprendizaje hacia otros programas; en al ámbito social de igual forma se encuentra poco difundido principalmente por la inacción de los gobiernos locales a través de sus respectivas instituciones o instancias. La idea es entonces, sistematizar la práctica constante y permanente de las personas en forma individual o colectiva, sin importar el tipo de actividad que haga (popular, escolar, colegial, universitario, federado o de alto nivel), aunque la definición marque una determinada línea, que da más énfasis en los sectores con mayores necesidades y de más bajos recursos.

De acuerdo con Martínez (2003), el conocimiento de la realidad para saber que hacer para transformarla, supone una herramienta básica para que posteriormente, se pueda planificar, programar y establecer estrategias de actuación efectivas. Asimismo, resulta también necesario alcanzar una visión totalizadora de la situación problema (necesidades - carencias) de manera que se puedan priorizar según el entorno y de acuerdo con los recursos existentes para atenderlas.

Ahora bien, el problema de la aplicación de los métodos al estudio de las necesidades físico deportivas y recreativas no es tanto problema de la utilización de tal o cuál método o de la dificultad o capacidad para hacerlo, sino de que el propio objeto de la investigación, es decir de la necesidades 


\section{MHSalud}

URL www.una.ac.cr/mhsalud

ciudadanas reales, ya que éstas son muy cambiantes o pueden serlo y por ello es necesario considerar que para el ámbito del servicio deportivo y recreativo municipal del que se ha venido hablando, siempre resultarán necesidades deportivas normativas (en esencia definidas por expertos, profesionales o administradores), comparativas (obtenidas de indicadores socioeconómicos), sentidas (demanda potencial) y manifestadas (demanda real); todas la cuales a su vez conforman de forma particular el núcleo prioritario de evaluación para cada nivel-contexto de planificación del servicio deportivo y recreativo municipal (planes "políticos-técnicos", programas, proyectos y desarrollo y cambio social). (Martínez, 2003, pp. 7)

Para la puesta en marcha de un plan de oferta del servicio de deporte y recreación municipal, básicamente se esta hablando de acciones y/o actividades relativas a mejorar y mantener la calidad de vida, el bienestar y la salud en general de sus pobladores como fines máximos, así como, las relativas a la participación colectiva de manera que dentro de sus lineamientos generales se pueda mencionar:

- Emplear la actividad física, la recreación y el deporte como un medio formativo tanto de actitudes como de comportamiento de cara a la sociedad.

- Introducir al niño, joven y adultos en la práctica constante de las actividades físicodeportivas como parte de su estilo de vida.

- Elevar el nivel técnico - deportivo de los practicantes y por consiguiente del cantón.

- Trabajar mancomunadamente con el asociacionismo recreativo y deportivo, sin superponer actividades.

Se verá entonces que programas y actividades de estos se pueden ofrecer como servicios a la ciudadanía en general.

\subsubsection{1.- PROGRAMAS}

- Escuelas deportivas y recreativas municipales básicas

- Escuelas recreativas de vacaciones

- Escuelas de iniciación deportiva

- Escuelas deportivas específicas

Existe una amplia oferta en esta materia o al menos modelos para su desarrollo. En general, la idea es comenzar con la enseñanza de varios deportes en el niño sin ningún tipo de ambición desmedida en lo competitivo, a efectos de contribuir con una base formativa integral y de base motriz sólida para que posteriormente, si tiene posibilidades físicas, síquicas y lo desea pueda practicar actividades competitivas de mayor nivel.

\section{Sus objetivos pueden ser:}

- Iniciar, promover y divulgar en el niño las distintas modalidades de actividad, recreación física y deporte, o de uso positivo de su tiempo libre por medio de estas.

- Educar en la actividad física, la recreación, el deporte y el uso positivo del tiempo libre a niños, jóvenes y adultos. 
- Crear un espacio de participación general.

- Detectar, apoyar y evaluar los talentos deportivos.

- Trabajar conjuntamente en el desarrollo de estas actividades con los clubes, centros educativos y asociaciones deportivas y recreativas.

\section{Características a considerar:}

- Permitir el ingreso de niños, jóvenes y adultos sin ningún tipo de discriminación.

- Llevar las escuelas a los barrios de la comunidad.

- Propiciar la integración y participación de los padres en el desarrollo de la escuela.

- Crear un ambiente de convivencia y de responsabilidad entre los miembros de la escuela.

- Desarrollar las escuelas cuya demanda aseguren la permanencia de la misma.

- Propiciar el crecimiento sicomotriz del niño sin adelantar su madurez natural.

- Excluir cualquier prueba de ingreso para el acceso de los niños a las diferentes modalidades de escuelas propuestas.

- Abarcar con las escuelas la más amplia franja de edades.

- Establecer horarios acordes a los requerimientos y a las necesidades de los usuarios o clientes y muy especialmente de los escolares.

\section{Otras consideraciones...}

En el servicio que se da, se debe aprovechar al máximo los recursos de la comunidad, como materiales, infraestructura y otros, llevándolo a barrios, escuelas, colegios, clubes y otras entidades. Además, se podrá enfatizar también en el desarrollo de juegos tradicionales o aquellos que fomenten la cultura.

Otro aspecto importante es que, las clases deben ser impartidas por profesionales en el campo de la educación física, la recreación, el deporte, y procurar que se lleven a cabo en un ambiente de convivencia entre los alumnos, el profesor o instructor a efectos de que la actividad que realice el niño sea creativa y divertida.

\section{Nivel de atención:}

De acuerdo con Stoppani (2000), depende de la especificidad de la escuela; en el caso de las recreativas y multideportivas, se puede iniciar con clases mixtas con niños de 8 a 12 años y principiantes de mayor edad, con grupos de no más de 20 chicos. Para el caso de las escuelas donde ya existe un nivel de especialización mayor, también se puede desarrollar con clases mixtas o no, a partir de los 10 u 11 años aproximadamente. Y para el caso de las personas con discapacidad, éstas deberán organizarse y esto depende del tipo de discapacidad, el grado de complejidad de la misma y la capacidad funcional de las personas asistentes.

\section{Ubicación, horario, calendario:}

Se recomienda desarrollarlas en cualquier instalación deportiva construida para tal fin o adecuar las existentes según las necesidades. El horario debe ser a convenir, según todas las partes y preferiblemente durante todo el año. En el caso de los más chicos se recomienda dos veces por 


\section{MHSalud}

URL www.una.ac.cr/mhsalud

semana de 45 a 90 minutos de acuerdo a las características del grupo, y por razones de madurez anatómico-fisiológicas, sicológica y motriz.

\section{Personal docente (profesor o instructor)}

Es necesario plantear que deberán estar a cargo de las escuelas aquellos profesionales cuyo perfil cumpla claramente con una formación en educación física, recreación y deportes, sobre todo sostener la concepción educativa-recreativa-deportiva en ese orden, con excepción de las escuelas de alto nivel competitivo, ya que lo que interesa es fomentar los conocimientos en los niños e incrementar su gusto por la práctica de la actividad física, la recreación y el deporte como parte de su propio estilo de vida.

\section{Instalaciones y materiales:}

Para el ICODER y desde el Consejo Nacional del Deporte y la Recreación es clara su política nacional de no supeditar los programas a la existencia de instalaciones, es decir, que éstas no son indispensables para el desarrollo de los diversos programas que se proponen implementar en todas las comunidades del país. Este espíritu es el que interesa promover de igual forma en las comunidades, y reconocer de manera integral sus diferencias y posibilidades, por ello en el caso de las escuelas recreativas y deportivas para llevarlas a la práctica, no hacen falta grandes instalaciones, espacios abiertos, polideportivos, gimnasios u otros lugares, sino dar cabida a la creatividad y utilizar los recursos existentes en la comunidad tratando de optimizarlos al máximo. Hay que recordar que en la medida en que aumente la especialización, los requerimientos serán también superiores.

En cuanto a los materiales, de igual forma, no hacen falta los más sofisticados, sino que por el contrario en los inicios hasta se puede utilizar el material elaborado por los niños. Sí es importante tener presente que cuando se trabaja con menores, los elementos y materiales deben estar adaptados a la edad y nivel que poseen, en cuanto peso, tamaño, etc. La cantidad tampoco debe ser un determinante inicial, de manera que si no se tienen los suficientes, será necesario establecer formas metodológicas con el objeto de rotarlos y de esa manera obtener mejores resultados con todos los participantes.

\section{Programación y Planificación:}

Estos aspectos estarán relacionados con los objetivos que se proponga el Comité, y este debe responder al plan cantonal aprobado; de todas formas el programa podrá ser uno solo y general para todas las escuelas, cualquiera que sea su tipo, mientras que la planificación podrá establecerse para cada una en particular.

\section{Normativa:}

En este apartado básicamente se referirá a las normas de funcionamiento que le son propias en general al programa de las escuelas, y en particular a cada una de ellas, por ejemplo: derechos y deberes de los practicantes, profesores / instructores a cargo; cuidados de la instalación y del material deportivo, horarios de funcionamiento, etc.

Estas normas deberán estar escritas y aceptadas por todos, incluso por los alumnos y los padres. 


\section{JUEGOS DEPORTIVOS - RECREATIVOS MUNICIPALES (JUEGOS COMUNALES)}

Los juegos comunales, como se les conoce popularmente, son cada vez más una de las formas en las que mayor número de personas desean realizar actividades deportivas reglamentadas, independientemente del nivel técnico-deportivo que posean. Para unos representará su primera competencia y para otros será la culminación activa de su vida deportiva, previo paso por el deporte federado.

No obstante su sentido está en la oportunidad para participar en aquellas actividades con una estructura deportiva pero de carácter meramente recreativo que le permitan a las personas disfrutar de su derecho a la recreación físicamente activa y por supuesto con múltiples beneficios para su salud. O sea, nada más cercano al deporte de base y al popular, donde se posibilitará de forma real la práctica recreativa con cierto nivel competitivo, básico, libremente escogida por las personas.

Además, por organización, trascendencia y significado, esta es una de las mayores actividades que se pueden realizar en el orden municipal, por lo que cada Comité debe entender que será necesario poner el empeño en asegurar su éxito.

Sus objetivos pueden ser:

- Promover y proponer a la población del cantón una opción para la práctica de la actividad física el deporte y la recreación adaptada al nivel competitivo de los participantes y a la edad de los mismos, entre otras características propias de cada comunidad.

- Educar en la actividad física, la recreación, el deporte y el uso positivo del tiempo libre a niños, jóvenes y adultos.

- Crear un espacio de participación general.

- Detectar, apoyar y evaluar los talentos deportivos.

- Trabajar conjuntamente en el desarrollo de estas actividades con los clubes, centros educativos y asociaciones deportivas y recreativas.

- Involucrar activamente en la organización, a los líderes y fuerzas vivas de la comunidad.

\section{Niveles de participación:}

Podrán establecerse distintos niveles de participación y de competición, determinados por una serie de factores, principalmente del número de personas inscritas en las distintas actividades, pruebas y competencias. No obstante, sobre esta base, el Comité deberá analizar si la convocatoria es:

Abierta: donde se podrán inscribir todos los participantes en un solo evento, torneo, etc.

Mixta: es decir donde puedan participar grupos de diferentes edades a la vez, equipos integrados por hombres y mujeres, niveles de competición, otras características que sean propuestas por la organización pero que mantenga esta modalidad. 


\section{MHSalud}

URL www.una.ac.cr/mhsalud

Federada: donde sólo se podrán inscribir deportistas que se encuentran en esa condición o que estuvieron hasta dos años antes de la fecha de los juegos, por ejemplo.

Y una última, sería la combinación de los tres niveles antes descritos, tratando de que los juegos permitan la participación de todos los ciudadanos y evitar con ello caer en la exclusión por habilidades o destrezas en el deporte.

\section{Actividades y deportes:}

La organización y convocatoria en este sentido estará completamente ligada a la definición establecida en cuanto a los niveles de participación que desean promover. Así, puede darse de las siguientes formas:

$>$ Se establece una serie de actividades y deportes para todas las categorías o;

$>$ Se designa con base a cada categoría (nivel de participación) las actividades y deportes que en cada una se disputarán, sin olvidar la edad de los participantes.

Además, en cada municipio, la idea es que se programe las actividades y deportes que crean convenientes en función de la demanda, la experiencia y resultados positivos de años anteriores, la edad de los mayores participantes, y las instalaciones disponibles entre otras.

\section{Inscripciones:}

Una forma de realizar este proceso es permitiendo la libre inscripción de los interesados en forma individual o bien por equipos según la oferta planificada para los juegos, pero además, representantes de escuelas, colegios, escuelas deportivas, clubes, empresas, comercios, etc. Para ello, el lugar debe estipularse con la mayor anticipación posible, completando una planilla que contenga los datos generales del equipo y los individuales de cada participante, esto, para hacer más sencillo el trámite y que se pueda archivar para el siguiente año.

Otro aspecto, es que los organizadores pueden establecer un cupo mínimo y máximo de individuos o equipos participantes en determinadas actividades o deportes.

\section{Documentación:}

Será el comité organizador el que determine la documentación a presentar, pudiendo ser esta:

- Ficha de inscripción

- Ficha deportiva individual

- Cuota de inscripción (sí se estipula)

- Autorización de los padres para los menores de edad, etc.

\section{Organización:}

El personal encargado de la realización de esta actividad será el que desempeñe sus tareas de dirección de deportes, en este caso, esta actividad puede ser liderada por el Comité de Deportes y Recreación o una comisión integrada por diferentes instituciones y representantes de la comunidad. Incluso pueden integrarse además voluntarios y colaboradores que representen otros sectores interesados en apoyar un evento en la localidad o comunidad. 


\section{MHSalud}

URL www.una.ac.cr/mhsalud

Por otro lado, dependiendo de la complejidad y tamaño de los juegos, y con el objetivo de asegurar el correcto desenvolvimiento de los mismos, cada comité organizador podrá nombrar a su vez distintos organismos específicos de coordinación. Por ejemplo: Comité organizador, Comité de arbitraje, Comité de faltas, Comisión de prensa y mercadeo y otras.

\section{Instalaciones:}

De igual forma que para los programas de escuelas recreativas y deportivas, lo más importante es no supeditarlos a la existencia de instalaciones, es decir, que éstas no son indispensables para el desarrollo de los diversos programas que se proponen implementar en todas las comunidades del país. Este espíritu es el que interesa promover de igual forma y reconocer de manera integral sus diferencias y posibilidades, por ello el plan que interese desarrollar debe ser congruente con las posibilidades de uso de áreas físicas e instalaciones disponibles en la comunidad e incluso en aquellas privadas que hayan sido puestas a disposición del programa. Además, de dar la oportunidad de variar las sedes para llevar así el programa a otros lugares de la población y de esa manera favorecer su conocimiento.

\section{Materiales:}

En cuanto a los materiales, no hacen falta los más sofisticados o profesionales, sino que por el contrario en los inicios hasta se puede utilizar el más básico. Sí es importante tener presente que cuando se trabaje con niños, los elementos y materiales deben estar adaptados a la edad y nivel que posean, en cuanto peso, tamaño, etc. Como ya se había mencionado, la cantidad tampoco debe ser un determinante inicialmente, de manera que si no se tienen los suficientes, será necesario establecer formas metodológicas con el objeto de rotarlos y de esa manera obtener mejores resultados con todos los participantes.

En este aspecto se tiene varios elementos que es conveniente considerar y analizar por separado:

a. Materiales deportivos:

- Balones para cada uno de los deportes, principalmente deportes de conjunto.

- Varios; redes, tableros, cronómetros, etc.

- Premios; diplomas, medallas, trofeos, becas, productos de la zona, etc.

b. Materiales administrativos:

- Folletos promocionales (calcomanías, carteles, etc.)

- Fichas de inscripción

- Fichas individuales

- Reglamentos de participación y competición

- Actas y planillas de juego

- Carnés de organizadores, árbitros, invitados, etc.

- Fichas de control

c. Materiales de oficina:

- Artículos de oficina

- Fotocopiadora

- Computadora 


\section{MHSalud}

URL www.una.ac.cr/mhsalud

\section{Cuota de inscripción:}

Este aspecto debe quedar a criterio de cada municipio, sin embargo, si se cobra una cuota, está debe ser mínima para buscar con ello proteger el carácter social del los juegos y a su vez divida por categorías según las características de los participantes. Por ejemplo:

- Infantiles y juveniles

- Adultos

- Personas con discapacidad

- Adultos mayores

\section{Período de participación y competencia:}

Se fijará con base a la cantidad de actividades y de deportes convocados, a las instalaciones y áreas disponibles, a los participantes y equipos inscritos; que puedan desarrollarse desde un fin de semana para poblaciones pequeñas, hasta varios meses para comunidades con gran número de habitantes y buscar la escala de tiempo que más se ajuste a las necesidades de cada comunidad.

Una forma de definir la escala de tiempo para la organización de este tipo de actividades sería:

- Verano y periodo de vacaciones escolares. Comprende de diciembre hasta marzo aproximadamente.

- Parte del año; dividido por meses, bimestres, trimestres o semestres.

- Todo el año; planificado de manera que se realicen actividades en cada mes o la mayor parte de este, de forma continua y sistemática. Por ejemplo, de enero a noviembre, o un programa de actividades mayor a los seis meses.

- Permanente en el cantón; programa que se gestiona y planifica con una visión más allá del mismo período por el que esté nombrado el Comité, y trata así de que se convierta en una actividad sostenible y sustentable directamente por la misma comunidad.

Además, podrá establecerse anualmente y con la suficiente antelación, el período en que se llevará a cabo la actividad, con mencionar lo siguiente:

- Fase de información, de ... a ...

- Fase de inscripción, de .... a ...

- Fase de participación o competencia, de ... a ...

\section{Premios:}

Una actividad tan importante como esta necesita de gratificación, que puede ir desde un simple diploma por la participación hasta trofeos, medallas, becas, un día-mes gratis de uso de las instalaciones deportivas, etc. Todo ello para crear un mejor incentivo que aliente a la gente a una mayor participación y adherencia a los programas. Lo importante es, sin embargo, que la motivación no esta dada únicamente por la posibilidad de ganar un premio, sino que se logre una integración cada vez mayor de las personas en este tipo de actividades y con ello se fomente una 


\section{MHSalud}

URL www.una.ac.cr/mhsalud

práctica permanente de actividades físicas deportivo-recreativas en beneficio de la salud de la misma población.

\section{Otras consideraciones...}

Faltarían una serie de detalles los cuales deben de completarse al elaborar la reglamentación general de los juegos. En todo caso se mencionan algunas de ellas:

- $\quad$ Sistema de puntuación

- Diagrama de cada actividad o competencia

- Horarios de las actividades y juegos

- Costo de los árbitros

\section{LOS CLUBES RECREATIVOS Y DEPORTIVOS}

Los Clubes Recreativos son grupos con diferentes actividades en donde cada persona puede gastar su tiempo libre en hacer aquello que le gusta, ya que por medio de ellos, las personas pueden identificar a otras con intereses afines, para intercambiar criterios y experiencias, asociarse voluntariamente y organizarse para hacer lo que a todo ese grupo de personas afines les gustaría, y para lo cual desarrollan diversas actividades de forma organizada.

El programa de Clubes Recreativos es una propuesta de promoción de la actividad física, el deporte y la recreación impulsado por el ICODER para todos los cantones del país, con el fin de promover el gusto y el hábito de la actividad física y del uso activo del tiempo libre en todas las personas, sin importar la edad o la condición física de cada cual. Este modelo constituye una forma más que puede ser implementada a través de los Comités como estrategia para incorporar y motivar a los diferentes sectores de la población de su cantón a participar de actividades de esparcimiento, disfrute y por supuesto de beneficio para su salud física, mental y emocional (Roque, 2003).

\section{¿Cómo se forman y qué intereses pueden poseer los Clubes Recreativos?}

Los clubes se forman por personas interesadas en un tipo específico de actividad recreativa o deportiva: voleibol, baloncesto, ciclismo, artes marciales, atletismo, danza aeróbica, paseos exploración en la naturaleza, deportes de aventura, patines, entre otras muchas actividades posibles.

Los que están interesados se reúnen con el apoyo de un promotor recreativo cantonal y deciden que actividad hacer. Además, la idea es que elaboren un plan recreativo que requiera en lo posible de mínimos recursos, así como, en el caso de requerirlos, de conocer las vías para poder obtenerlos, para que una vez que estén organizados empiecen a realizar las actividades deseadas en el horario que les convenga.

\section{LAS CALLES RECREATIVAS}

Similar al programa de clubes impulsado por el ICODER para todos los cantones del país, las Calles Recreativas es un tipo de actividad de amplia participación que nació en Colombia y se ha extendido rápidamente a otros países. Como su nombre lo dice, la idea es utilizar las calles de la ciudad o comunidad en los fines de semana, donde hay menos tráfico y pueden ser cerrados por periodos cortos de tiempo ( 2 hasta 4 horas), con el fin de celebrar en ellas muchas actividades 


\section{MHSalud}

URL www.una.ac.cr/mhsalud

diversas de recreación como: caminatas, ciclismo recreativo, patinetas, juegos infantiles, juegos cooperativos, aeróbicos, baile, y muchas otras (Roque, 2003).

Ahora bien, en Costa Rica este diseño inicial se ha ampliado al uso máximo de todos los espacios que una comunidad pueda disponer para la recreación de sus habitantes, y aprovechar por ejemplo: canchas multiuso al aire libre, gimnasios, salones comunales, lotes baldíos, es decir, cualquier lugar sirve para la recreación.

Así, los fines de semana, especialmente los domingos los promotores recreativos que han sido destacados en cada cantón del país y contratados por los Comités o el ICODER, en coordinación con los líderes comunales y los Comités Comunales de Deporte y Recreación, asociaciones deportivas y recreativas, ONGs, instituciones, etc., deben organizar Calles Recreativas en la cabecera del cantón y también otras localidades más alejadas que tengan una situación de carencia de estos servicios, o que presenten situaciones sociales que las hagan merecedoras de una atención especial.

De modo tal, que las Calles Recreativas son actividades para toda la familia y todos los grupos sociales, por lo que deben tener una oferta que interese a la mayor parte de los habitantes del cantón.

\section{Otras consideraciones...}

En cuanto a los aspectos de mayor detalle que deben de completarse al elaborar el programa para la organización de las calles (actividades), es importante no olvidar considerar lo siguiente:

- Plan de difusión (básico), utilizar los medios disponibles en la localidad

- Diagrama de cada actividad o competencia

- Horarios de las actividades y juegos

Materiales deportivos y recreativos:

- Balones para cada uno de los deportes, principalmente de conjunto.

- Varios; redes, tableros, cronómetros, etc.

- Concursos y premios; diplomas, medallas, becas, productos de la zona, etc.

Finalmente, que las Calles Recreativas constituyen un medio que conducen a celebrar los Juegos Comunales del cantón, y que representan la fiesta comunitaria que culmina una vida recreativa y físico - deportiva que puede ser realizarse una semana al año, o lo largo de este como se explicó con anterioridad.

\section{SERVICIO MUNICIPAL DE NATACIÓN}

Esta actividad es sumamente importante ya que ejerce una acción preventiva sobre la población, mayormente infantil; que en la época de verano utiliza los ríos, lagos y mares para disfrutar y sofocar los efectos del calor, y que puede provocar a veces y por la imprudencia, pérdidas de vida.

Para desarrollar un programa de este tipo indudablemente se debe contar con una piscina, requerimiento que es caro, pero que sin embargo, a lo largo de las últimas dos décadas en el país se ha iniciado un proceso de dotación de piscinas en ciertos lugares con motivo de la celebración de eventos mayores como los Juegos Deportivos Nacionales. En ese sentido, la intencionalidad de un programa de esta naturaleza es aprovechar las instalaciones como piscinas o balnearios existentes en 


\section{MHSalud}

URL www.una.ac.cr/mhsalud

beneficio de la población, principalmente las de carácter público o municipales, pero en caso de no contar con ellas, también existe la posibilidad de suscribir convenios con alguna entidad privada.

La metodología de trabajo, los contenidos y los objetivos de cada uno de los cursos que se puedan ofrecer como parte del servicio de este programa, deberán ser estipulados por cada administración con base a su compromiso con la población y a sus necesidades.

\section{Objetivos:}

- Desarrollar aptitudes, habilidades y destrezas en medio distinto al habitual (medio acuático)

- Establecer los conocimientos necesarios para participar en programas deportivos recreativos comunitarios

\section{Nivel de atención:}

Deberá ser estipulado por cada servicio deportivo y recreativo municipal. A modo de ejemplo y de acuerdo con Stoppani (2000) seria:

- Curso de ambientación (de 2 a 5 años)

- Curso de iniciación ( 6 y 7 años)

- Curso de aprendizaje para niños (de 8 a 12 años)

- Curso de aprendizaje para adultos (de 14 años en adelante)

- Curso de perfeccionamiento para niños (8 años en adelante)

- Curso de mantenimiento físico para adultos

- Entrenamiento de equipo de competición

\section{Ubicación, Horario y Calendario:}

En piscinas o balnearios acondicionados al efecto, en horario a estipular por la administración (Ejemplo: Comité de Deportes, Asociación de Natación); y el calendario se determinará con base a los objetivos que cada municipio o localidad se plantee.

\section{JUEGOS DEPORTIVOS ESCOLARES (JUEGOS DEPORTIVOS ESTUDIANTILES)}

Los Juegos Deportivos Estudiantiles es un programa del Estado costarricense el cual es ejecutado por el ICODER y el Ministerio de Educación Pública. Estos juegos representan una oportunidad a todo estudiante nacional del nivel escolar y colegial de poder utilizar su tiempo libre en la práctica de actividades deportivas y recreativas, además, de propiciar el desarrollo de habilidades y destrezas que favorezcan la formación integral de los mismos.

En cuanto a las líneas básicas y generales, estas vienen a ser similares a las del programa Juegos Comunales, por lo que cada Comité podrá tomar la decisión de organizar unos juegos exclusivos para su comunidad o formar parte de un movimiento mayor e integrarse al programa nacional.

\section{Objetivos:}

- Promover la participación activa de la comunidad estudiantil mediante la actividad física, deportiva y recreativa. 


\section{MHSalud}

URL www.una.ac.cr/mhsalud

- Coadyuvar al desarrollo de habilidades y destrezas del estudiante por medio de la Educación Física, el Deporte y la Recreación.

- Proveer al país de talentos deportivos que contribuyan a mejorar el rendimiento deportivo en estas diferentes disciplinas.

\section{Deportes en los que se puede participar:}

El programa comprende dieciocho deportes tanto individuales como de grupo y para ambos sexos: Ajedrez, Atletismo (pista y campo), Baloncesto, Fútbol, Natación, Fútbol salón, Tenis de mesa, Gimnasia, Balonmano, Triatlón, Voleibol, Taekwondo, Fútbol sala, Ciclismo de montaña, Coreografía aeróbica, Judo y Karate Do.

En estos deportes participan niños (as) y adolescentes entre los 7 y los 17 años, en las 20 regiones del país que se divide el sector educación.

\section{Ubicación, Horario y Calendario:}

En las instalaciones deportivas de los centros educativos (escuelas y colegios) públicos y privados, instalaciones municipales o del Estado, en horario a estipular por la sede escogida por el Ministerio de Educación, preferentemente fuera del escolar y en cualquier época del año.

\section{JUEGOS DEPORTIVOS NACIONALES}

Los Juegos Deportivos Nacionales es el programa de deporte competitivo más importante que tiene el ICODER y es el evento deportivo más grande de Costa Rica. Actualmente, este consta de dos etapas o fases: eliminatoria regional y final nacional. En la primera etapa se supone o espera que se de un amplio desarrollo y promoción de este, y la última etapa es completamente competitiva donde asisten los mejores deportistas clasificados del país.

Para llevar a cabo cada una de las etapas, la participación de los Comités Cantonales es fundamental, ya que gracias a ellos el programa recibe el mayor número de participantes y personas involucradas en la ejecución de las actividades e implementación de los distintos procesos eliminatorios, de ahí, que su participación en él es sumamente importante contribuyendo durante todo el proceso junto al ICODER en la detección, formación y preparación de atletas en el país. (Roque, 2004).

\section{Objetivos.}

- Ejecutar un programa de promoción y competición deportiva para los jóvenes del país, que permita la exaltación de los valores éticos, sociales y culturales para contribuir a la formación integral de los ciudadanos.

- Promover la participación de los jóvenes en el deporte en todas las regiones el país.

- Promover la competición deportiva en el ámbito nacional entre las agrupaciones deportivas. 


\section{MHSalud}

URL www.una.ac.cr/mhsalud

\section{Deportes en los que se puede participar:}

El programa comprende quince deportes tanto individuales como de grupo y para ambos sexos: Ajedrez, Natación, Fútbol salón, Tenis de mesa, Atletismo (pista y campo), Voleibol, Triatlón, Tenis de campo, Baloncesto, Ciclismo de montaña, Boxeo, Béisbol, Fútbol, Ciclismo de ruta y Halterofilia.

En estos deportes participan adolescentes entre los 12 y los 20 años, en las 10 regiones del país que se divide el ICODER.

\section{Ubicación, Horario y Calendario:}

En las instalaciones deportivas de los centros educativos (escuelas y colegios) públicos y privados, instalaciones municipales o del Estado, en horario a estipular por la sede escogida por el Consejo Nacional del Deporte y la Recreación, preferentemente fuera del período escolar durante todo el año, y culminando idealmente con la fase final en enero del año siguiente.

Como se ve, son muchos los programas y proyectos que se pueden desarrollar en el seno de las comunidades y en especial bajo la coordinación conjunta de los Comités Cantonales, las municipalidades, las diferentes organizaciones gubernamentales y no gubernamentales, los líderes comunales y el Estado Central; lo importante es considerar como se ha venido hablando, todos los aspectos (humanos, materiales, económicos, legales, etc.), y en especial de las necesidades y demandas de los ciudadanos para poder ofrecer un mejor servicio en función de sus demandas, pero también gestionar de una mejor manera los recursos con fines públicos asignados bajo administración.

\section{2.- EL PLAN DE GESTIÓN DE INSTALACIONES Y EQUIPAMIENTOS PARA LA OFERTA DEL SERVICIO DEPORTIVO Y RECREATIVO MUNICIPAL}

Para entender el concepto de la gestión de instalaciones y áreas físicas para la práctica de la actividad física, el deporte y la recreación en el ámbito comunitario, es necesario entender también que el mismo responde al concepto de necesidad social que de acuerdo (Martínez, 2003, pp. 9), es inherente a la idea de un servicio social, y más si cabe cuando se reconoce la práctica de actividades físico deportivas como derechos de la ciudadanía que justifican su servicio público y por ser subvencionadas con presupuestos provenientes de los impuestos municipales y del Estado. De manera que, su alcance y significado es el propio de cualquier otro plan, es decir, hace referencia a las decisiones de carácter general que expresan los lineamientos políticos fundamentales del municipio y del Estado costarricense, de las prioridades que se derivan de esas formulaciones, de la asignación de los recursos acorde a esas prioridades, de las estrategias de acción o intervención y el conjunto de medios o instrumentos que se van a utilizar para alcanzar las metas y objetivos propuestos.

La Gestión de las instalaciones resume diferentes acciones, como ser el mantenimiento, el uso, la promoción y la evaluación de las mismas. Esta responsabilidad comienza en el instante en el que el municipio se hace cargo de un equipamiento a través de sus diferentes instancias, ya sea por transferencia, convenio, construcción u otros motivos. El objeto de una gestión eficiente estará dado por garantizar un correcto funcionamiento, mejorar al máximo el servicio a brindar llegando al 


\section{MHSalud}

URL www.una.ac.cr/mhsalud

mayor número de personas beneficiadas y economizando las funciones de los directivos y empleados.

\subsection{1.- USO DE LAS INSTALACIONES}

Para lograr una efectiva gestión debe dictarse una serie de normativas con el objeto de elaborar lo que se podría llamar un reglamento de utilización de los equipamientos deportivos en general, y si es necesario de cada una de las instalaciones en particular.

\section{Consideraciones a tomar en cuenta:}

Normas generales; se debe definir que es una instalación deportiva municipal, quienes podrán utilizarlas y de que forma y con que clase de deportes o actividades.

Usos prioritarios; consiste en definir que sectores de la población tendrán prioridad en su uso, y se considera siempre la razón de ser de la instalación y del servicio que en ella se brinda, pero además, en apego a las políticas y lineamientos nacionales que favorecen en la medida de las posibilidades a los sectores más desfavorecidos o desatendidos (niñez, estudiantes, adultos mayores, personas con discapacidad, etc.).

Alquiler de equipamientos; estipular si las instalaciones deportivas municipales podrán alquilarse o no, si se diera la primera condición, deberá fijarse el tiempo de transporte, el costo, a quienes, las formas del convenio, la presentación y la forma de las solicitudes, los casos en que se realicen espectáculos y se cobre una entrada, etc.

Los usuarios; a quienes se considera así o clientes, que derechos y que deberes tendrán, que régimen de faltas y sanciones se estipulará, etc.

Órganos de control; el director de la instalación y su consejo de administración, si lo hay, deberán consignar diferentes formas y órganos de control con el objeto de evaluar el funcionamiento de las actividades y del buen uso de las instalaciones.

\subsection{2.- LA INSTALACIÓN DEPORTIVA Y SU DIRECCIÓN}

Al hablar de un equipamiento deportivo y recreativo público municipal, a partir de los más importantes es indispensable que la misma sea orientada por un responsable técnico-administrativo, se retoma aquí la esencia de este aspecto traducido en el marco de las políticas nacionales para el desarrollo del deporte y la recreación, la cual consiste en promover la utilización y optimización en el uso de los recursos existentes en cada comunidad del país y que están administrados por los Comités bajo delegación de las municipalidades, pero que no pretende promover la idea de supeditar las posibles acciones a realizar y el logro de los objetivos en el ámbito comunitario a la variable instalación física o realización de nuevas inversiones como única vía de respuesta a las necesidades concretas, que además debe ser sostenible.

\section{Características de dirección (funciones):}




\section{MHSalud}

URL www.una.ac.cr/mhsalud

Administrativas; inscripción, registro de los potenciales usuarios o clientes de los servicios.

Financieras; controlar la venta de entradas en las instalaciones, redactar y supervisar los contratos de los distintos servicios, autorizar los pagos a los distintos proveedores de los diferentes productos requeridos en la instalación y subservicios.

Técnicas; programar los horarios generales para el uso de las instalaciones deportivas, controlar el material deportivo en uso y petición de nuevas compras.

Mantenimiento; planificar nuevas construcciones y mejoras al mantenimiento de las instalaciones, encargar los materiales/productos necesarios para ello y la limpieza de los locales.

Personal; controlar al personal efectivo que se ha contratado para que desempeñe funciones en la instalación, establecer los horarios de trabajo correspondientes, autorizar los cambios de turno del personal técnico, de mantenimiento y vigilancia.

\subsection{3.- LA PROMOCIÓN Y LA PUBLICIDAD}

Se puede tener las mejores instalaciones, infraestructura, equipos y profesionales pero si no hay usuarios o clientes, cada uno de esos servicios será inútil.

Cómo formas o estrategias para resolver este aspecto se pueden mencionar:

$\checkmark \quad$ Lanzar una efectiva campaña en todos los medios periodísticos locales, tanto radiales como escritos y televisivos si los hubiere y fuese factible.

$\checkmark$ Promover un slogan a utilizarse en toda campaña, que tenga en cuenta que llegue a los niños, jóvenes y población adulta.

$\checkmark$ Promocionar beneficios como entradas gratuitas para menores de edad, los ancianos, personas con discapacidad, entre otros.

$\checkmark$ Emitir tarjetas de uso de las instalaciones o sus servicios con un cierto número de entradas y un valor agregado al usuario o cliente (p.ej.: descuento en la membresía por el pago de un trimestre completo o anualidad, una entrada gratuita a algún evento deportivo, etc.).

$\checkmark$ Promover en determinados días u horarios una reducción de tarifas.

$\checkmark$ Promover un ambiente agradable y sobre todo seguro dentro de la instalación.

\subsection{4.- LA FINANCIACIÓN DE EQUIPAMIENTOS}

Aspectos a considerar:

Propiciar el uso social y público de las instalaciones. Público no significa que las personas tengan siempre un uso gratis del servicio.

$\checkmark$ Proponer formulas de cooperación y coopatrocinio con otras entidades.

$\checkmark$ Controlar al máximo los gastos que demande el funcionamiento.

$\checkmark$ Analizar convenientemente el cobro de entradas o tasas de uso.

Proponer el alquiler, la publicidad y la organización de espectáculos para subvencionar la gestión de los equipamientos. 


\subsection{5.- METODOLOGÍA DE EVALUACIÓN DE UNA INSTALACIÓN DEPORTIVA O RECREATIVA}

El objetivo de ésta es lograr un instrumento que permita medir lo más objetivamente posible los resultados de las acciones emprendidas en un equipamiento deportivo tipo, por ello y de acuerdo con Stoppani (2000), propone considerar los siguientes aspectos metodológicos dentro una conveniente gestión de la instalación.

\section{Informe de los profesores, técnicos:}

Este se puede realizar diario o semanalmente, según se estipule, por los profesores o técnicos que se encuentran a cargo de las clases y con diferentes datos sobre la misma; deporte, nivel de grupo, fecha, horario, alumnos, observaciones, etc.

\section{Informe de la actividad:}

Este es elaborado por los encargados de cada actividad o por los jefes de cada uno de los departamentos estipulados, los datos a recabar pueden ser: período, actividad, número de grupos, clases dadas, cantidad de participantes, instructores, profesores, etc.

\section{Reporte de practicantes:}

Este se refiere a encuestas aplicadas al azar a los practicantes, que expresen opinión por las actividades que realizan, como así también las condiciones en que encuentran la instalación, la disposición de los funcionarios, etc.

\section{Supervisión de profesores y técnicos:}

Realizada directamente por el personal técnico y administrativo de la instalación, contiene: actividad, grupo, nivel, inscritos, fecha, tema de la clase, objetivos, etc.

\section{Uso de la instalación:}

Tiene por finalidad conocer la productividad de ella, queda a criterio de quienes evalúen su estructura definir cuales serán sus contenidos: deporte, capacidad de la instalación, número de alumnos y otros.

Una forma de establecer el uso de la instalación sería definir el porcentaje de uso dividiendo la capacidad de la instalación entre el número de beneficiarios atendidos.

\section{3.- EL PLAN DE GESTIÓN ADMINISTRATIVA Y FINANCIERA DEL SERVICIO DEPORTIVO Y RECREATIVO MUNICIPAL}

Este plan surge en diversos momentos del proceso planificador del servicio, donde inicialmente se proponen y estructuran del plan recreativo y deportivo cantonal o de la comunidad, los cuales a su vez también deberían estar en consonancia con las políticas y estrategias nacionales para el desarrollo del deporte y la recreación. 


\section{MHSalud}

URL www.una.ac.cr/mhsalud

En función de este plan, se conforma el correspondiente plan económico que dará soporte financiero a todo lo demás. Posterior a ello, una vez aprobados definitivamente los presupuestos municipales y en su contexto las respectivas partidas solicitadas para la ejecución de este, deben reajustarse los planes previstos adaptándolos a la realidad económica disponible que permita su real ejecución, de este modo, una vez en marcha la ejecución de los proyectos emanados de los programas que componen el plan, empieza a ejecutarse.

De acuerdo con Mestre y García (1999), sin un plan económico-contable realista, resulta imposible al mismo tiempo que ilegal, llevar a cabo todos los demás planes, o cualquiera de ellos. Así pues, se trata de uno que no tiene una finalidad como tal en sí mismo, resulta imprescindible para poder llevar a la práctica o ejecutar todos los demás.

\subsection{1.- INGRESOS PROPIOS}

Al hablar de ingresos para el deporte y la recreación, se sobreentiende el respaldo económico para hacer frente a todas cuantas actividades se programen. Queda claro que debe existir cualquiera que sea el modo de gestión, una partida de ingresos destinada presupuestariamente a suplir las necesidades financieras que determinan la ejecución de los planes establecidos y que se concretan de manera tangible en el servicio que se ofrece a los usuarios o clientes, como se les quiera ver.

En apego a los estipulado en la Ley 7794 a saber "Código Municipal y su Legislación Conexa", del 30 de abril de 1998, los Comités Cantonales según el artículo 170, coordinarán con la Municipalidad respectiva lo concerniente a inversiones y obras en el Cantón (Municipio). Para ello los municipios deberán asignarles de acuerdo con lo estipulado en la Ley, un mínimo de un tres por ciento de los ingresos ordinarios anuales municipales, que se distribuirá en un diez por ciento máximos para gastos administrativos y el resto para programas deportivos y recreativos. En ese sentido, se denota claramente que, ese primer financiamiento del servicio deportivo y recreativo municipal corresponde al Estado representando por las Municipalidades de cada cantón en manos de los gobernantes locales elegidos, lo cual denota una clara y evidente responsabilidad social. (Código Municipal, 2001).

Por otro lado, en la misma ley, en su artículo 171, se indica que los Comités Cantonales, responsables de la ejecución y oferta de ese servicio deportivo y recreativo en el municipio, podrán ceder en administración las instalaciones deportivas y recreativas de su propiedad mediante convenios. Lo anterior indica, que los Comités quedan facultados para gozar del usufructo de las instalaciones deportivas y recreativas bajo su administración, y que los recursos se aplicarán al mantenimiento, mejoras y construcción de las mismas instalaciones. (Código Municipal, 2001).

Finalmente, siguiendo con la misma ley, en su artículo 172, se establece que en la primera semana de julio de cada año, los Comités someterán a conocimiento de los Consejos Municipales sus programas anuales de actividades, obras e inversión, antes de aprobarse los presupuestos ordinarios de la municipalidad, a lo cual deberán presentar un informe de los resultados de la gestión correspondiente al año anterior. (Código Municipal, 2001).

Queda claro, que los fondos disponibles para hacer frente a la prestación del servicio deportivo y recreativo en el municipio podrán provenir en primera instancia del presupuesto central de las municipalidades o gobiernos locales como lo dicta la Ley 7794, y en segunda de los productos resultantes del servicio prestado (alquileres de instalación, precios por cursos, entradas a 


\section{MHSalud}

URL www.una.ac.cr/mhsalud

espectáculos en los recintos deportivos, etc., ...), por donativos o auxilios, y por cantidades expresamente consignadas para tal fin en el presupuesto ordinario o extraordinario de la entidad deportiva responsable, para el caso que nos refiere este modelo, los Comités Cantonales de Deportes y Recreación.

En cuanto al presupuesto, de acuerdo con Mestre y García (1999), éste puede definirse como la expresión contable para un período de tiempo determinado, generalmente un año del plan económico de la Hacienda Pública o, en el caso de la gestión directa mediante un órgano especial de la fundación pública de servicios y como parte integrante de aquella. Para la elaboración del mismo es importante considerar una serie de fases sucesivas y vinculadas entre si:

1. Elaboración del presupuesto, propiamente

2. Su aprobación, previa discusión

3. Ejecución presupuestaria a lo largo del período

4. Control. Ejercido normalmente de tres formas, administrativa o interna, jurisdiccional o externa, o política.

\subsection{2.- CARACTERÍSTICAS DEL PRESUPUESTO ANUAL}

$\checkmark$ Se trata de un elemento estimativo anticipado, una previsión de funcionamiento. Es en este caso una declaración de intenciones de lo que se desea hacer en el año venidero.

$\checkmark \quad$ La aprobación de un presupuesto se considera como una previsión normativa que obliga a la entidad a su fiel cumplimiento, recordando que esta obligación lo es tanto política como judicial, fundamentalmente en lo referente a los gastos.

$\checkmark \quad$ La redacción de un presupuesto y consiguiente aprobación, supone una relación equilibrada entre ingresos y gastos.

$\checkmark$ Esta relación de gastos y de ingresos debe expresarse según la legislación y normativa vigente, es decir, lenguaje contable generalizado mediante las respectivas partidas o cuentas presupuestarias.

Los presupuestos de una entidad, y principalmente de una entidad pública, tienen carácter continuo año tras año, de tal forma que no pueden producirse rupturas presupuestarias de un año para otro, y que todas las incidencias de la gestión queden reflejadas y contabilizadas.

La amplia participación democrática en la elaboración del plan de gestión administrativa y financiera debe garantizar el respaldo popular a las acciones en él incluidas, altos niveles de participación de la población en las actividades y el reconocimiento municipal de la importancia que tiene esta para la salud, el deporte y la recreación en su labor y la vida del cantón.

\subsection{3.- PLAZO TEMPORAL DEL PLAN}

Este tiene un plazo temporal de un año de duración, y debe concordar con los definidos por la Municipalidad dentro de su Plan Anual Operativo. Sin embargo, es conveniente que se definan objetivos y metas en un horizonte temporal más largo, que establezca una continuidad de acciones. Una alternativa es que el Comité Cantonal defina uno para su período de vigencia de dos años, que se subdividiría en dos planes de gestión presupuestaria anuales. 


\section{MHSalud}

URL www.una.ac.cr/mhsalud

\subsection{4.- COMPONENTES OPERATIVOS DEL PLAN}

Basados en la propuesta de políticas y estrategias nacionales para el desarrollo de la actividad física para la salud, el deporte y la recreación, la estructura básica del Plan debe contener los siguientes componentes (Roque, 2004):

a) Marco general

Es una información actualizada del Comité Cantonal de Deportes y Recreación que incluya su estructura organizacional, funciones, organigrama y recursos humanos. Es conveniente incluir aquí un diagnóstico organizacional que explique las fortalezas, oportunidades, debilidades y amenazas del Comité y su labor en el cantón y distritos.

Diagnóstico situacional del cantón en materia de actividad física para la salud, deportes y recreación, que incluya: instalaciones existentes, capacidad, nivel de uso y equidad en su disfrute, existencia de junta administrativa debidamente constituida, distribución geográfica, programas de actividades, tipo de actividades desarrolladas, de usuarios o clientes, sectores sociales, distritos y comunidades atendidos y no atendidos, distribución temporal de las actividades en el año, existencia de programas para vacaciones, etc.

b) Instituciones, organizaciones, asociaciones, clubes, grupos y personas interesadas que tienen o realizan programas de estos.

c) Matriz de desempeño Programático (MDP).

\begin{tabular}{|c|c|c|c|c|c|c|c|c|}
\hline $\begin{array}{l}\text { ACCION } \\
\text { ESTRATE- } \\
\text { GICA }\end{array}$ & $\begin{array}{l}\text { OBJETIVO } \\
\text { DE LA } \\
\text { ACCION }\end{array}$ & $\begin{array}{l}\text { PRODUC- } \\
\text { TOS }\end{array}$ & $\begin{array}{l}\text { UNIDAD } \\
\text { DE } \\
\text { MEDIDA }\end{array}$ & $\begin{array}{l}\text { PRODUCCIÓN } \\
\text { ESTIMADA }\end{array}$ & $\begin{array}{l}\text { RESUL- } \\
\text { TADOS } \\
\text { ESPE- } \\
\text { RADOS }\end{array}$ & $\begin{array}{l}\text { RESPON- } \\
\text { SABLE }\end{array}$ & $\begin{array}{l}\text { MONTO } \\
\text { Y } \\
\text { PARTIDAS }\end{array}$ & $\begin{array}{l}\text { ORIGEN } \\
\text { DE LOS } \\
\text { RECUR- } \\
\text { SOS }\end{array}$ \\
\hline
\end{tabular}

De sus elementos o componentes se identifica:

- Nombre del programa/subprograma/proyecto

- Misión del programa/subprograma/proyecto

- Acción estratégica: según las definidas como las políticas y estrategias nacionales para el desarrollo de la actividad física para la salud, el deporte y la recreación.

- Objetivos de la acción: son los propósitos generales que tiene cada una de las acciones y proyectos incluidos en el plan y que deben responder a los objetivos generales definidos en las políticas y estrategias nacionales para el desarrollo de la actividad física para la salud, el deporte y la recreación.

- Productos del programa: son los bienes y servicios organizacionales que producen los proyectos y acciones incluidas en el plan y que deben ser medibles de manera cuantitativa.

- Unidad de medida: es el elemento que permite cuantificar los bienes y servicios producidos en los proyectos y acciones del plan. Deben ser significativas, expresadas en términos simples y numéricos. 


\section{MHSalud \\ URL www.una.ac.cr/mhsalud}

- Cantidad de producción estimada en el semestre y el año: es el total de bienes y servicios que se planifican en el término del ejercicio presupuestario planificado, expresada en términos numéricos.

- Objetivos específicos: son los propósitos específicos de cada una de las acciones y proyectos incluidos y que deben derivarse de los objetivos generales definidos en las políticas y estrategias nacionales para el desarrollo de la actividad física para la salud, el deporte y la recreación. Objetivos de la Acción.

- Tipo de indicador: es la variable cuantitativa o cualitativa específica que permite medir el desempeño en cada proyecto o acción.

- Resultado esperado: es el valor cuantitativo específico de la meta a alcanzar en cada proyecto o acción, expresado en el indicador.

- Persona responsable: indicar quien se responsabiliza por la ejecución de cada proyecto o acción.

- Presupuesto por partidas y monto: se debe precisar la fuente del financiamiento, que es un mínimo del 3\% del presupuesto municipal, y su distribución entre todos los proyectos y acciones por partida o cuenta de gasto.

d) Presupuesto detallado: se debe adjuntar al plan para el año que se planifica, con base en el monto total asignado por la Municipalidad.

e) Anexos:

- Aval del Consejo Municipal

- Certificación de ingresos

\section{Referencias:}

Código Municipal y Legislación Conexa. Ley 7794. 2 ed. San José, Costa Rica. Editec Editores S.A. EDIT. IPECA S.A. 2001.

Campos, C. (2000). "Gestión y marketing del servicio de actividades físico-deportivas". http://www.efdeportes.com/ Revista Digital - Buenos Aires - Año 5 - Nº 22 - Junio 2000.

Martínez, D. (2003). "Una propuesta teórica de planificación deportiva municipal: la base de los proyectos deportivos". Rev.int.med.cienc.act.fis.deporte - número 12, diciembre 2003 ISSN: 1577-0354. http://cdeporte.rediris.es/revista12/artplanificación.html.

Mestre, J., García, E. (1999). "La gestión del deporte municipal". 2 ed. Barcelona, España. INDE Publicaciones.

Mosquera, A. (2004). "El servicio deportivo y recreativo municipal. Modelo de gestión para su desarrollo. Propuesta de un modelo de gestión del servicio deportivo - recreativo municipal que brindan los Comités Cantonales de Deporte y Recreación". Tesis sometida a la consideración del Tribunal Examinador del Programa de Posgrado en Gerencia de la Salud para optar por el título de Master en Gerencia de la Salud. Instituto Centroamericano de Administración Pública. ICAP. San José, Costa Rica. 


\section{MHSalud}

URL www.una.ac.cr/mhsalud

Roque, R. (2004). Documento "Políticas y Estrategias para el Desarrollo de la Actividad Física para la Salud, el Deporte y la Recreación en los Cantones del País”. Plan Nacional de Fortalecimiento y Acreditación de los Comités Cantonales de Deporte y Recreación. ICODER. San José, Costa Rica.

Roque, R. (2003). "Promotores Recreativos Cantonales. Recreación y Salud." Boletín del Área de Recreación del ICODER, v. 1, nº 2 del 01 octubre. ICODER. San José, C.R. 2003.

Stoppani, J. (2000). "El servicio deportivo y recreativo municipal". Madrid, España. Editorial Gymnos Deportiva.

Fecha de recepción del artículo: 03 de marzo del 2007.

Fecha de aceptación del artículo: 10 de mayo del 2007.

Fecha de publicación del artículo: 31 de diciembre del 2007. 